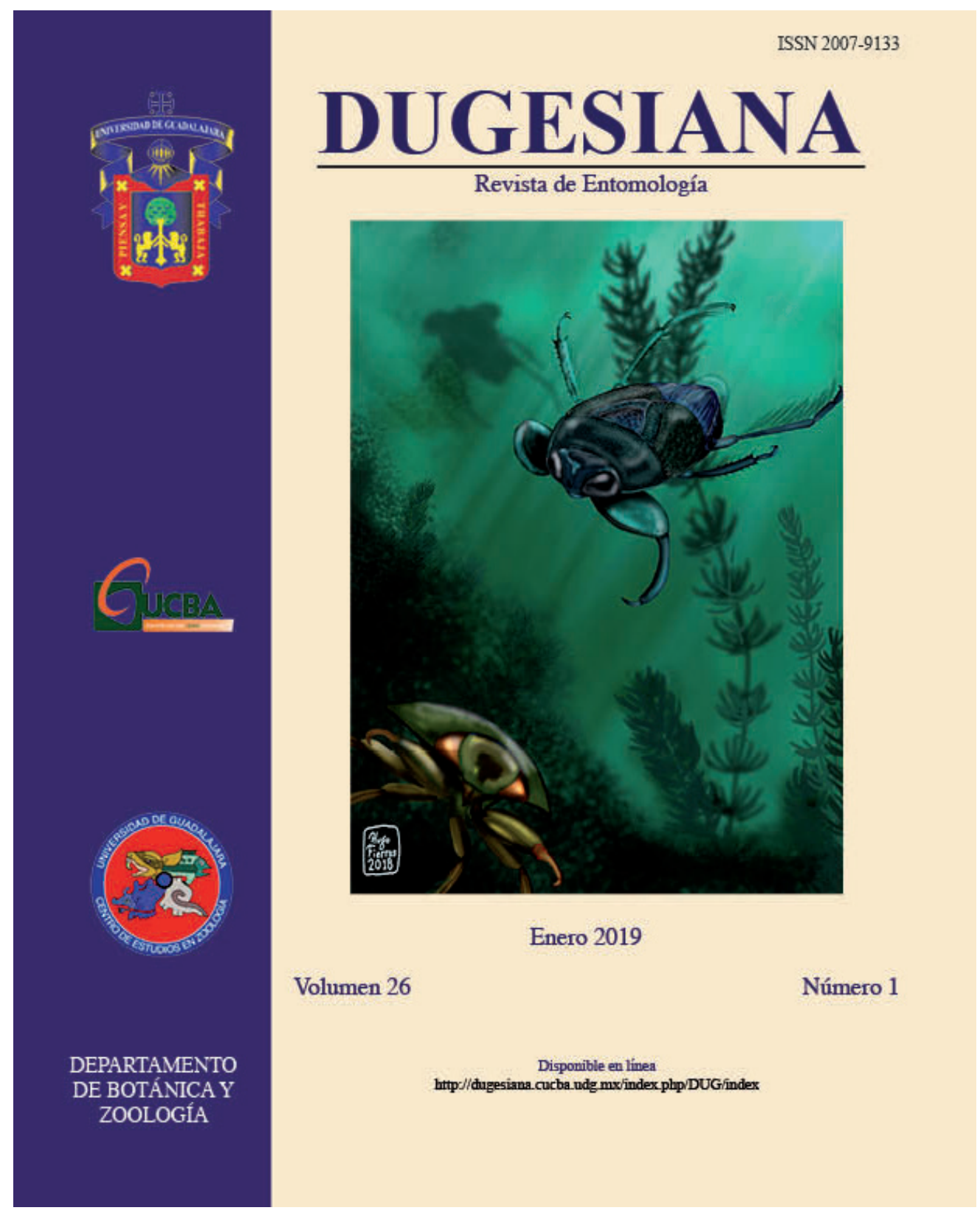

DUGESIANA, Año 26, No.1, 2019 (primer semestre de 2019) es una publicación Semestral editada por la Universidad de Guadalajara, a través del Centro de Estudios en Zoología, por la División de Ciencias Biológicas y Ambientales, CUCBA. Km. 15.5 carr. a Nogales, Predio Las Agujas s/n, Nextipac, C.P. 45100. Zapopan, Jalisco, México. Tel. 37771150, http://dugesiana.cucba.udg.mx/index.php/DUG/index, glenusmx@gmail.com, Editor responsable: José Luis Navarrete Heredia. Reserva de Derechos al Uso Exclusivo 04-2009-062310115100-203, ISSN: 2007-9133, otorgados por el Instituto Nacional del Derecho de Autor. Responsable de la última actualización de este número: José Luis Navarrete Heredia, Editor y Ana Laura González-Hernández, Asistente Editorial. Fecha de la última modificación 1 de enero de 2019, con un tiraje de un ejemplar.

Las opiniones expresadas por los autores no necesariamente reflejan la postura del editor de la publicación.

Queda estrictamente prohibida la reproducción total o parcial de los contenidos e imágenes de la publicación sin previa autorización de la Universidad de Guadalajara. 


\title{
Primer registro de Pseudomyrmex gracilis (Fabricius, 1804) (Hymenoptera: Formicidae: Pseu- domyrmecinae) para Durango, México
}

\author{
First record of Pseudomyrmex gracilis (Fabricius, 1804) (Hymenoptera: Formicidae: Pseudomyrmecinae) for \\ Durango, México
}

\begin{abstract}
Miguel Angel Soto-Cárdenas ${ }^{1 *}$, Miguel Vásquez-Bolaños ${ }^{2}$, Isaias Chairez-Hernández ${ }^{1}$ Miguel Mauricio Correa-Ramírez ${ }^{1}$, Jesús Lumar Reyes-Muñoz ${ }^{1}$ 'Centro Interdisciplinario de Investigación para el Desarrollo Integral Regional, Unidad Durango, Instituto Politécnico Nacional, Sigma 119 Fracc. 20 de Noviembre II, 34220 Durango, Durango, México.*miguelsoto06@hotmail.com, ichairez@hotmail.com, miguel.m.correa.ramirez@gmail.com, reyesjlrm@gmail.com. ${ }^{2}$ Entomología, Centro de Estudios en Zoología, Departamento de Botánica y Zoología, Centro Universitario de Ciencias Biológicas y Agropecuarias, Universidad de Guadalajara, Km. 15.5 Carr. Nogales, Las Agujas, Zapopan, Jalisco. 45110, México. Apdo. Postal 134.mvb14145@hotmail.com*Autor de correspondencia.
\end{abstract}

El género Pseudomyrmex Lund, 1831 se incluye dentro de la tribu Pseudomyrmecini de la subfamilia Pseudomyrmecinae. Se distribuye solo en el continente Americano, donde es común encontrarlo en las regiones tropicales y subtropicales. Vive principalmente sobre ramas de árboles vivos o muertos y en hojas de una amplia variedad de plantas. Algunas especies de este género mantienen asociaciones estrictas (defensa) con ciertas especies de plantas del género Acacia (Ward 1990). Para México se han registrado 43 especies que presentan una amplia distribución (Vásquez-Bolaños 2015). En el estado de Durango se han reportado dos especies de este género: $P$. apache y P. pallidus (Vásquez-Bolaños 2015).

Pseudomyrmex gracilis (Fabricius, 1804) fue descrita en Sudamérica, es una de las especies más grandes y vistosas del género (Fabricius 1804; Ward 1985). Actualmente, su distribución conocida abarca desde el sur de los Estados Unidos de América (Alabama, California, Carolina del Sur, Hawái, Florida, Luisiana, Mississippi y Texas) hasta el norte de Argentina (Buenos Aires, Córdoba, La Rioja y Santa $\mathrm{Fe}$ ), en donde, de acuerdo con MacGown y Hill (2010) y Wetterer (2010) en la mayoría de estos estados de los Estados Unidos de América se presenta como una especie invasora, sin embargo en México no presenta esta condición (AntMaps 2018; AntWiki 2018 ). En México se ha registrado en 18 entidades federativas (Vásquez-Bolaños 2015).

La especie alcanza tallas de entre 7.5 a $10 \mathrm{~mm}$; su color es extremadamente variable, desde el negro unicolor (con los apéndices más claros) hasta el marrón naranja unicolor. Se caracteriza por presentar una cabeza amplia y densamente punteada con una apariencia subopaca a sublúcida (pero sin llegar a ser mate), casi tan larga como ancha y con el margen anterior del lóbulo mediano recto a ampliamente convexo, así como redondeado lateralmente; pronoto dorsolateralmente marginado pero no bruscamente; formula palpal 6,4 y margen masticatorio de la mandíbula con 7-10 dientes; ojos grandes y alargados; el mesonoto en vista lateral es más inclinado que la cara basal del propodeo; el pecíolo es largo y delgado con un pedúnculo anterior distinto; la pilosidad es común en el mesosoma dorsal y en la cara externa de las tibias (Ward 1993).

El 27 de diciembre de 2017 en la localidad de La Joya, municipio del Mezquital, Durango, se recolectaron en un Bosque Tropical Caducifolio (BTC) tres ejemplares de obreras que fueron determinadas como P. gracilis. Los especímenes se recolectaron sobre un árbol de tescalame Ficus sp. El sitio de recolecta presentó un alto grado de perturbación, con pocos terrenos de cultivo y utilizado como sendero para el pastoreo de ganado. Las recolectas se realizaron entre las 15:00 y las 17:00 horas, cuando los indivudos se encontraban caminando. Para la determinación de los ejemplares se consultó la información depositada en AntWeb 2018 y AntWiki. Esta observación representa el primer registro de la especie para el estado de Durango. Esta especie llega a establecerse en zonas rurales, es común encontrarla anidando y forrajeando en arboles de una gran viariedad de especies (tanto nativas como introducidas) $\mathrm{y}$ en troncos que son utilizados para cerca en campos de cultivo corrales de ganado.

Material examinado: Tres obreras. Etiquetadas de la siguiente manera: México, Durango, San Francisco del Mezquital, La Joya, 1480 msnm, 27.XII.2017, BTCpert, $23^{\circ} 27^{\prime} 59^{\prime \prime} \mathrm{N}$ y $104^{\circ} 22^{\prime} 08^{\prime \prime} \mathrm{O}$, ex: Ficus sp., M.A. SotoCárdenas colector. El material se depositó en la Colección Entomológica del Centro de Estudios en Zoología de la Universidad de Guadalajara (CZUG).

\section{AGRADECIMIENTOS}

Al Instituto Politécnico Nacional proyecto SIP: 20170564 (parte del proyecto multidisciplinario 1808), por las facilidades prestadas para realizar el presente trabajo. A los revisores por sus comentarios. 


\section{LITERATURA CITADA}

AntMaps. 2018. antmaps.org. Recuperado el 7 de Febrero de 2018, de http://antmaps. org $/$ ?mode $=$ species\&species $=$ Pseudomyrmex.gracilis

AntWiki. 2018. antwiki.org. Recuperado el 7 de Febrero de 2018, de http://www.antwiki.org/wiki/Pseudomyrmex gracilis

Fabricius, J. C. 1804. Systema Piezatorum secundum ordines, genera, species adjectis synonymis, locis, observationibus, descriptionibus. Reichard, Brunsviga.

MacGown, J. A. y J. G. Hill. 2010. Two New Exotic Pest Ants, Pseudomyrmex gracilis and Monomorium floricola (Hymenoptera: Formicidae) Collected in Mississippi. Midsouth Entomologist, 3(2): 106-109.

Vásquez-Bolaños, M. 2015. Taxonomía de Formicidae (Hymenoptera) para México. Métodos en Ecología y Sistemática, 10(1), 1-53.

Recibido: 4 de abril de 2018

Aceptado: 17 de julio de 2018

Primero en línea: 26 de noviembre de 2018

First Online: 26th November 2018
Ward, P. S. 1985. The Neartic species of the genus Pseudomyrmex (Hymenoptera: Formicidae). Quaestiones Entomologicae, 21(2): 209-246.

Ward, P. S. 1990. The ant subfamily Pseudomyrmecinae (Hymenoptera: Formicidae): generic revision and relationship to other formicids. Systematic Entomology, 15(4): 449-489.

Ward, P. S. 1993. Systematic studies on Pseudomyrmex acacia-ants (Hymenoptera: Formicidae: Pseudomyrmecinae). Journal of Hymenoptera Research, 2(1): 117-168.

Wetterer, J. K. 2010. Worldwide Spread of the Graceful Twig Ant, Pseudomyrmex gracilis (Hymenoptera: Formicidae). Florida Entomologist, 93(4): 535-540.

Whitcomb, W., H. Denmark, W. Buren and J. Carroll. 1972. Habits and present distribution in Florida of the exotic ant, Pseudomyrmex mexicanus (Hymenoptera: Formicidae). Florida Entomologist, 55(1): 31-33. 